el 4 : Kompilasi Hasil Uji Sifat fisika terbaik dari kulit imitasi untuk atasan sepatu

\begin{tabular}{|c|c|c|c|c|c|}
\hline \multirow[t]{2}{*}{ Jenis Ujis Fisi } & \multirow[t]{2}{*}{ Kode } & \multirow{2}{*}{$\begin{array}{l}\text { Tebal } \\
\text { (MM) } \\
\end{array}$} & \multicolumn{2}{|c|}{ Hasil Uji } & \multirow{2}{*}{$\begin{array}{c}\text { Syarat Mutu SIl } \\
\text { SII. } 1645 \cdot 85\end{array}$} \\
\hline & & & DOP + Parafinic & Formula I & \\
\hline \multicolumn{6}{|l|}{ Kuat tarik } \\
\hline - Membujur & P. $60.4 \mathrm{bg}$ & 1,03 & $1.993,77$ & 911,72 & $\operatorname{Min} 750 \mathrm{~N} / \mathrm{Cm}^{2}$ \\
\hline - Melintang & P.60.6 bg & 1,07 & 825,08 & 729,35 & $\operatorname{Min} 700 \mathrm{~N} / \mathrm{cm}^{2}$ \\
\hline \multicolumn{6}{|l|}{ Mulur } \\
\hline - Membujur & P. $60.6 \mathrm{bg}$ & 1,07 & 33,33 & 64,07 & Maks. $70 \%$ \\
\hline - Melintang & P. $60.6 \mathrm{bg}$ & 0,95 & 51,05 & 74,48 & Maks. $80 \%$ \\
\hline \multicolumn{6}{|l|}{ Kuat Sobek } \\
\hline - Membujur & P.60.4 bg & 0,89 & 68,17 & 63,19 & $\operatorname{Min} 45 \mathrm{~N} / \mathrm{Cm}^{2}$ \\
\hline - Melintang & P.95.6 bg & 0,92 & 55,21 & 31,72 & $\mathrm{Min} 30 \mathrm{~N} / \mathrm{Cm}^{2}$ \\
\hline \multicolumn{6}{|l|}{ Kuat Rekat } \\
\hline - Membujur & P. 60.4 bg & 0.96 & 2,20 & 1,47 & $\operatorname{Min} 0,3 \mathrm{~N} / \mathrm{Cm}^{2}$ \\
\hline - Melintang & P. 60.4 bg & 0,96 & 2,61 & 1,78 & Min $0,6 \mathrm{~N} / \mathrm{Cm}^{2}$ \\
\hline Kekatanan kikis & P. $60.4 \& 5$ bg & & 0,23 & 0,46 & Mkas. $1 \%$ \\
\hline \multicolumn{6}{|l|}{ Kuat jahit } \\
\hline - Membujur & P.95.6 bg & 0,95 & 439,82 & 428,33 & $\mathrm{Min} 50 \mathrm{~N} / 5 \mathrm{Cm}$ \\
\hline - Membujur & P.60.4 bg & 0,96 & 292,67 & 240,25 & $\operatorname{Min} 45 \mathrm{~N} / 5 \mathrm{Cm}$ \\
\hline Ketahahan bengkuk & & & Tidak retak & Tidak retak & Ticiak retak \\
\hline
\end{tabular}

Majalah Barang Kulit, Karet dan Plastik

\section{PENELITIAN MUTU PLASTIK BUSA UNTUK JOK MOBIL}

\author{
Oleh : Niken Karsiati, Adi Slamet Supriyadi, Sunardi
}

\section{ABSTRACT}

The research is aimed at determining the quality of foam plastic for automobile cushions in order that it can be employed as the basic of decoding quality standard in the framework of ensuring the quality and application. Samples are taken from the manufacturers and markets. The physical tests are carried-out in accordance with the methods as stated in ASTM, IIS, GM and SNI, and the data obtained can be presented as following : density (37.1 - 54.9) $\mathrm{kg} / \mathrm{m} 3$; hardness $\emptyset 200 \mathrm{~mm}, 25 \%$ ( $13.0-57.6)$; ball rebound resilience ( $41-63$ ) \%; tensile strength $(0.53-1.03) \mathrm{kg} / \mathrm{cm} 2$, elongation at break ( $62.83-112.5) \%$, tearing strength $(0.37-0.76) \mathrm{kg} / \mathrm{cm} 2$ dan compression set ( $4.13-11.65) \%$.

\section{INTISARI}

Penelitian ini bertujuan untuk mengetahui mutu plastik busa untuk jok mobil sehingga dapat digunakan sebagai dasar penentuan standar mutunya guna menjamin kualitas dan penggunaannya. Pengambilan contoh dilakukan di perusahaan dan di pasaran. Pengujian sifat fisika berdasarkan metode yang diambil dari pustaka ASTM, JIS, GM dan SNI. Dari hasil penelitian diperoleh data sebagai berikut : kerapatan massa $(37,1-54,9) \mathrm{kg} / \mathrm{m} 3$, kekerasan $\emptyset 200 \mathrm{~mm}, 25 \%$ ( 13,0 - 57,6), kepegasan pantul ( $41-63) \%$, tegangan putus ( $0,53-1,03) \mathrm{kg} / \mathrm{cm} 2$, perpanjangan putus $(62,83-112,5) \%$, ketahanan sobek $(0,37-0,76$ ) $\mathrm{kg} / \mathrm{cm} 2$ dan pampat tetap $(4,13-11,65) \%$.

\section{PENDAHULUAN}

Pada Pelita VI saat ini perkembangan industri kendaraan bermotor khususnya kendaraan bermotor roda empat terus meningkat dengan pesat. Seiring dengan lajunya perkembangan kendaraan bermotor tersebut, maka kebutuhan terhadap komponennya juga semakin meningkat. Salah satu komponen kendaraan bermotor yang cukup besar peranannya dan dalam jumlah yang banyak adalah plastik busa untuk jok mobil.

Plastik busa untuk jok mobil mempunyai fungsi yang cukup penting, yaitu untuk kenyamanan selama mengendarai kendaraan, sehingga dapat mengurangi rasa cepat lelah.

Plastik busa untuk jok mobil ini merupakan produk plastik yang dibuat dari bahan plastik thermoset ditambah dengan beberapa bahan pembantu diantaranya blowing agent. Adapun proses pembuatannya pada umumnya diproses dengan cara casting foam dengan menggunakan bahan baku plastik poliuretan. Pada prinsipnya proses pembuatannya ada 3 tahap atau phase, yaitu phase cair,

Vol. XII No. 24 Th. 1996/1997 
phase pengembangan dan phase stabilisasi struktur. Dengan proses casting foam tersebut alat cetakannya terdiri dari dua bagian yang terpisah, yaitu bagian bawah dan bagian atas. Mula-mula bahan baku dan bahan pembantu diantaranya blowing agent dan katalisator dimasukkan dalam alat pencampur (mixer). Kecepatan dan waktu pencampuran sangat menentukan bentuk busa yang terjadi, yaitu makin cepat putaran mixernya, maka akan semakin lembut busa yang dihasilkan. Hasil kocokan yang sudah membentuk sellulair dituang kedalam cetakan bagian bawah, kemudian ditutup rapat maka kompon akan mengisi seluruh cetakan. Setelah melewati waktu curing yang ditentukan, kemudian dikeluarkan dari cetakan dan dilakukan finishing.

Agar plastik busa yang dihasilkan dapat sesuai dengan fungsinya maka harus mempunyai sifat atau mutu tertentu sesuai dengan standar mutu yang diacu. Adapun sifat-sifat fisika yang penting yang berhubungan erat dengan mutu plastik busa untuk jok mobil diantaranya kerapatan massa, kekerasan, kepegasan pantul, tegangan putus, perpanjangan putus, ketahanan sobek dan pampat tetap.

Pada saat ini plastik busa untuk jok mobil sudah banyak diproduksi didalam negeri dan beredar dipasaran dalam berbagai jenis dan merk. Sedangkan mutunya juga sangat bervariasi, ada yang mutunya baik, tahan lama dan enak dipakainya namun ada juga yang baru sebentar dipakai sudah kempes dan cepat sobek.

Oleh karena sampai saat ini di Indonesia belum ada standar mutunya dan juga melihat kenyataan tersebut diatas, maka perlu diadakan suatu penelitian mutu terhadap plastik busa untuk jok mobil sehingga dapat digunakan sebagai dasar penentuan standar mutunya guna menjamin kualitas dan penggunaannya.

\section{MATERI DAN METODA}

1. Mater

1.1 Bahan

Plastik busa yang sudah dicetak sesuai bentuk dan ukuran jok mobil, sebanyak 10 jenis.

\subsection{Peralatan}

Timbangan analitik, mistar, cutter, alat uji kekerasan busa, alat uji pampat tetap, alat uji kepegasan pantul, alat uji kuat tarik.

\section{Metoda}

\subsection{Sampling}

Pengambilan sampel dilakukan di perusahaan plastik busa untuk jok mobil, karoseri kendaraan roda empat dan di pasaran di wilayah DKI Jakarta, Jawa Tengah dan Daerah Istimewa Yogyakarta. Sampel yang diambil terdiri dari beberapa jenis atau merek, bentuk dan ukuran dalam berbagai kualitas. Jumlah sampel untuk masing-masing jenis harus cukup untuk satu seri pengujian dan ulangannya.

\subsection{Pemberian Kode}

Semua contoh uji yang diperlukan diberi kode sesuai dengan ciri-ciri sampel. Adapun kode contoh uji adalah A, B, C, D, E, F, G, H, I dan J.

\subsection{Cara Pengujian}

Semua contoh uji terlebih dahulu diamati terhadap keadaan dan kenampakannya, yaitu antara lain permukaan contoh uji harus rata, tidak boleh ada cacat yang berupa lubang-lubang, sobek dan retak. Kemudian sebelum dilakukan pengujian, cuplikan yang sudah dibuat dikondisikan terlebih dahulu dalam ruangan yang bersuhu $(27 \pm 2)^{\circ} \mathrm{C}$ dan kelembaban relatih $(65 \pm 5) \%$ selama minimal 24 jam.

\subsection{Jenis Pengujian}

Pengujian mutu yang dilakukan merupakan uji sifat fisika yang terdiri dari uji kerapatan massa, kekerasan, kepegasan pantul, tegangan putus, perpan-jangan putus, ketahanan sobek dan pampat tetap. Adapun metoda ujinya berdasarkan pustaka standar antara lain ASTM D 3574-91, General Motor 6293 M-1993, JIS K 6401-1980 dan SNI 06-1004-1989.

\section{HASIL PENELTTLAN DAN PEMBAHASAN}

\section{Hasil Penelitian}

Hasil penelitian merupakan hasil uji sifat fisika plastik busa untuk jok mobil yang meliputi uji kerapatan massa, kekerasan, kepegasan pantul, tegangan putus, perpanjangan putus, ketahanan sobek dan pampat tetap. Pengujian dilakukan sebanyak tiga kali ulangan, seperti yang terlihat pada tabel berikut. 
Tabel . Data Hasil Uji Sifat Fisika Plastik Busa Untuk Jok Mobil

\begin{tabular}{|c|c|c|c|c|c|c|c|c|c|c|c|c|c|c|c|}
\hline \multirow[t]{2}{*}{ No } & \multirow[t]{2}{*}{ Kode } & \multicolumn{2}{|c|}{$\begin{array}{c}\text { Kerapatan } \\
\text { Massa } \\
(\mathrm{kg} / \mathrm{cm} 2)\end{array}$} & \multicolumn{2}{|c|}{$\begin{array}{c}\text { Kekerasan } \\
\sigma 200,25 \% \\
(\mathrm{~kg})\end{array}$} & \multicolumn{2}{|c|}{$\begin{array}{c}\text { Kepegasan } \\
\text { Pantul } \\
(\%)\end{array}$} & \multicolumn{2}{|c|}{$\begin{array}{c}\text { Tegangan } \\
\text { Putus } \\
(\mathrm{kg} / \mathrm{cm} 2)\end{array}$} & \multicolumn{2}{|c|}{$\begin{array}{c}\text { Perpanjang } \\
\text { an Putus } \\
(\%)\end{array}$} & \multicolumn{2}{|c|}{$\begin{array}{c}\text { Ketahanan } \\
\text { Sobek } \\
(\mathrm{kg} / \mathrm{cm} 2) \\
\end{array}$} & \multicolumn{2}{|c|}{$\begin{array}{c}\text { Pampat } \\
\text { Tetap } \\
(\%)\end{array}$} \\
\hline & & data & \begin{tabular}{|l|} 
rata- \\
rata
\end{tabular} & data & $\begin{array}{l}\text { rata- } \\
\text { rata }\end{array}$ & data & $\begin{array}{l}\text { rata- } \\
\text { rata }\end{array}$ & data & $\begin{array}{l}\text { rata- } \\
\text { rata }\end{array}$ & data & \begin{tabular}{|l|} 
rata- \\
rata
\end{tabular} & data & \begin{tabular}{|l|} 
rata- \\
rata
\end{tabular} & data & $\begin{array}{l}\text { rata- } \\
\text { rata }\end{array}$ \\
\hline 1. & A. & $\begin{array}{l}56,4 \\
53,7 \\
54,6 \\
\end{array}$ & 54,9 & $\begin{array}{l}54,9 \\
60,1 \\
57,8 \\
\end{array}$ & 57,6 & $\begin{array}{l}60 \\
59 \\
64 \\
\end{array}$ & 61 & $\begin{array}{l}0,72 \\
0,75 \\
0,87 \\
\end{array}$ & 0,78 & \begin{tabular}{|l|}
81,5 \\
81,5 \\
87,5 \\
\end{tabular} & 83,5 & \begin{tabular}{|l|}
0,49 \\
0,49 \\
0,52 \\
\end{tabular} & 0,50 & $\begin{array}{l}3,75 \\
5,21 \\
3,43 \\
\end{array}$ & 4,13 \\
\hline 2. & B. & $\begin{array}{l}52,8 \\
57,2 \\
54,4 \\
\end{array}$ & 54,8 & $\begin{array}{l}46,1 \\
43,5 \\
45,4 \\
\end{array}$ & 45,0 & $\begin{array}{l}61 \\
62 \\
63 \\
\end{array}$ & 62 & \begin{tabular}{|l|}
0,53 \\
0,43 \\
0,46 \\
\end{tabular} & 0,47 & \begin{tabular}{|l|}
88,0 \\
88,0 \\
69,0 \\
\end{tabular} & 81,66 & \begin{tabular}{|l|}
0,35 \\
0,32 \\
0,44 \\
\end{tabular} & 0,37 & $\begin{array}{l}7,36 \\
8,93 \\
8,13 \\
\end{array}$ & 8,14 \\
\hline 3. & C & $\begin{array}{l}48,3 \\
44,6 \\
42,7 \\
\end{array}$ & 45,2 & $\begin{array}{l}45,0 \\
41,8 \\
47,9 \\
\end{array}$ & 44,9 & $\begin{array}{l}59 \\
57 \\
58 \\
\end{array}$ & 58 & \begin{tabular}{|l|}
0,68 \\
0,62 \\
0,66 \\
\end{tabular} & 0,65 & \begin{tabular}{|l|}
87,5 \\
81,5 \\
94,0 \\
\end{tabular} & 87.67 & \begin{tabular}{|l|}
0,41 \\
0,38 \\
0,35 \\
\end{tabular} & 0,38 & \begin{tabular}{|c|}
8,70 \\
10,15 \\
9,60 \\
\end{tabular} & 9,48 \\
\hline 4. & D & $\begin{array}{l}41,8 \\
46,5 \\
48,5 \\
\end{array}$ & 45,6 & $\begin{array}{l}28,7 \\
34,6 \\
39,3 \\
\end{array}$ & 30,5 & $\begin{array}{l}55 \\
58 \\
58 \\
\end{array}$ & 57 & $\begin{array}{l}0,77 \\
0,84 \\
0,78 \\
\end{array}$ & 0,80 & \begin{tabular}{|l|}
75,0 \\
81,5 \\
62,5 \\
\end{tabular} & 73,0 & \begin{tabular}{|l|}
0,58 \\
0,67 \\
0,55 \\
\end{tabular} & 0,57 & \begin{tabular}{|l|}
8,41 \\
5,78 \\
7,30 \\
\end{tabular} & 7,16 \\
\hline 5. & $E$ & $\begin{array}{l}44,4 \\
48,0 \\
46,3 \\
\end{array}$ & 46,3 & \begin{tabular}{|l|}
38,0 \\
34,6 \\
29,9 \\
\end{tabular} & 37,3 & $\begin{array}{l}60 \\
64 \\
62 \\
\end{array}$ & 62 & $\begin{array}{l}0,57 \\
0,61 \\
0,55 \\
\end{array}$ & 0,58 & \begin{tabular}{|l|}
75,0 \\
87,0 \\
75,0 \\
\end{tabular} & 79,17 & \begin{tabular}{|l|}
0,36 \\
0,41 \\
0,33 \\
\end{tabular} & 0,37 & \begin{tabular}{|c|}
10,06 \\
9,85 \\
8,23 \\
\end{tabular} & 9,39 \\
\hline 6. & $F$ & $\begin{array}{l}37,0 \\
38,4 \\
35,9 \\
\end{array}$ & 37,1 & \begin{tabular}{|l|}
11,9 \\
14,1 \\
13,0 \\
\end{tabular} & 13,0 & $\begin{array}{l}60 \\
65 \\
67 \\
\end{array}$ & 64 & \begin{tabular}{|l|}
0,84 \\
0,70 \\
0,68 \\
\end{tabular} & 0,74 & \begin{tabular}{|l|}
73,0 \\
76,0 \\
76,0 \\
\end{tabular} & 75,0 & \begin{tabular}{|l|}
0,44 \\
0,50 \\
0,47 \\
\end{tabular} & 11,60 & \begin{tabular}{|l|}
10,41 \\
11,60 \\
12,64 \\
\end{tabular} & 11,55 \\
\hline 7. & $\bar{G}$ & $\begin{array}{l}43,2 \\
41,4 \\
40,8 \\
\end{array}$ & 41,8 & \begin{tabular}{|l|}
19,1 \\
17,4 \\
16,9 \\
\end{tabular} & 17,8 & \begin{tabular}{|l|}
65 \\
61 \\
63 \\
\end{tabular} & 63 & $\begin{array}{l}0,66 \\
0,63 \\
0,66 \\
\end{array}$ & 0,65 & \begin{tabular}{|l|}
74,5 \\
70,5 \\
80,0 \\
\end{tabular} & 75,0 & \begin{tabular}{|l|}
0,42 \\
0,45 \\
0,45 \\
\end{tabular} & 0,44 & \begin{tabular}{|l|}
5,91 \\
7,40 \\
8,31 \\
\end{tabular} & 7,21 \\
\hline 8. & $\mathrm{H}$ & $\begin{array}{l}45,3 \\
46,4 \\
45,4 \\
\end{array}$ & 45,7 & $\begin{array}{l}22,8 \\
24,7 \\
23,3 \\
\end{array}$ & 23,6 & $\begin{array}{l}58 \\
62 \\
60 \\
\end{array}$ & 60 & $\begin{array}{l}0,57 \\
0,65 \\
0,67 \\
\end{array}$ & 0,63 & \begin{tabular}{|l|}
64,5 \\
61,5 \\
63,0 \\
\end{tabular} & 63,0 & $\begin{array}{l}0,38 \\
0,44 \\
0,41 \\
\end{array}$ & 0,41 & \begin{tabular}{|l|}
4,56 \\
6,15 \\
7,40 \\
\end{tabular} & 6,04 \\
\hline y. & 1 & $\begin{array}{l}43,2 \\
42,4 \\
41,9 \\
\end{array}$ & 42,5 & $\begin{array}{l}29,1 \\
28,4 \\
25,6 \\
\end{array}$ & 27,7 & $\begin{array}{l}38 \\
43 \\
42 \\
\end{array}$ & 41 & $\begin{array}{l}0,96 \\
1,10 \\
0,88 \\
\end{array}$ & 0,98 & $\begin{array}{l}120,0 \\
105,5 \\
112,0 \\
\end{array}$ & 112,5 & \begin{tabular}{|l|}
0,39 \\
0,40 \\
0,47
\end{tabular} & 0,42 & \begin{tabular}{|l|}
5,35 \\
8,10 \\
6,24 \\
\end{tabular} & 6,56 \\
\hline 0. & $J$ & $\begin{array}{l}38,7 \\
40,3 \\
39,8 \\
\end{array}$ & 39,6 & $\begin{array}{l}15,6 \\
15,0 \\
12,0 \\
\end{array}$ & 14,2 & $\begin{array}{l}57 \\
62 \\
61 \\
\end{array}$ & 60 & $\begin{array}{l}1,04 \\
0,98 \\
1,07 \\
\end{array}$ & 1,03 & $\begin{array}{l}93,5 \\
96,0 \\
92,5 \\
\end{array}$ & 94,0 & \begin{tabular}{|l|}
0,54 \\
0,58 \\
0,51 \\
\end{tabular} & 0,51 & \begin{tabular}{|l|}
12,39 \\
10,92 \\
11,64 \\
\end{tabular} & 11,65 \\
\hline & $\begin{array}{c}\bar{x}= \\
S d=\end{array}$ & & $\begin{array}{l}45,35 \\
5,807\end{array}$ & & \begin{tabular}{|c|}
31,16 \\
14,842 \\
\end{tabular} & & $\begin{array}{c}58,8 \\
6,613\end{array}$ & & $\begin{array}{l}0,731 \\
0,1741\end{array}$ & & $\begin{array}{c}82,45 \\
13,556 \\
\end{array}$ & & $\begin{array}{l}0,444 \\
0,0674\end{array}$ & & \begin{tabular}{|l|}
8,13 \\
2,406
\end{tabular} \\
\hline
\end{tabular}

\section{Pembahasan}

Berdasarkan hasil penelitian dan pengujian sifat fisika plastik busa untuk jok mobil, diperoleh hasil bahwa mutu dari plastik busa tersebut sangat bervariasi. b. Kekerasan dan kepegasan pantul merupakan faktor penting dalam menentukan kualitas/mutu plastik busa. Hal ini disebabkan kedua sifat tersebut berpengaruh terhadap kenyamanan atau keenakan pakai jika plastik busa digunakan untuk jok. Apabila kekerasannya terlalu rendah atau terlalu tinggi, maka tidak terasa empuk jika plastik busa tersebut diduduki. Berdasarkan data uji, besarnya nilai kekerasan berkisar antara $(13,0-57,6)$ atau rata-rata 31,16 pada pengukuran dengan $\emptyset 200 \mathrm{~mm}$, ditekan sampai $25 \%$. sedangkan nilai kepegasan pantul berkisar antara (41-64) \% atau rata-rata $58,8 \%$.

c. Hasil uji tegangan putus adalah $(0,47-1,03) \mathrm{kg} / \mathrm{cm} 2$, dan perpanjangan putus antara $(63,0-112,5) \%$. Tegangan putus ini akan menggambarkan besarnya kekuatan plastik busa apabila mengalami penarikan. Sedangkan perpanjangan putus dimaksudkan untuk mengetahui sifat elastisitas dari plastik busa tersebut. Jika dalam rancangan standar ditetapkan nilai tegangan putus minimum 0,60 $\mathrm{kg} / \mathrm{cm} 2$ dan perpanjangan putus minimum $75 \%$, maka sampel yang tidak memenuhi persyaratan ada sekitar $20 \%$.

d. Ketahanan sobek akan berpengaruh pada daya tahan plastik busa bila digunakan terus menerus. Semakin tinggi ketahanan sobeknya, maka akan semakin tahan lama plastik busa tersebut dapat digunakan. Berdasarkan hasil uji, nilai ketahanan sobeknya adalah $(0,37-0,57) \mathrm{kg} / \mathrm{cm} 2$ atau rata-rata $0,44 \mathrm{~kg} / \mathrm{cm} 2$. Apabila dalam rancangan standar ditetapkan minimum $0,40 \mathrm{~kg} / \mathrm{cm} 2$, maka sampel yang tidak memenuhi persyaratan sekitar $20 \%$.

e. Pampat tetap dan kerapatan massa sangat berhubungan dengan sifat kekerasan plastik busa. Dalam pengujian pampat tetap, cuplikan dipampat sampai $50 \%$ dari tebal semula dengan waktu 22 jam pada suhu $70^{\circ} \mathrm{C}$. Berdasarkan hasil uji diperoleh data bahwa nilai kerapatan massa adaiah $(37,1-54,8) \mathrm{kg} / \mathrm{m} 3$ atau rata-rata $45,35 \mathrm{~kg} / \mathrm{nn} 3$, sedangkan pampat tetap berkisar antara $(4,13-11,65) \%$ atau rata-rata $8,13 \%$.

\section{KESIMPULAN}

Berdasarkan hasil penelitian dan pengujian ternyata mutu plastik busa untuk jok mobil sangat bervariasi.

Berdasarkan uji sifat fisika diperoleh hasil sebagai berikut : kerapatan massa $(37,1-54,9) \mathrm{kg} / \mathrm{m} 3$, kekerasan $\varnothing 200 \mathrm{~mm}, 25 \%(13,0$ - 57,6), kepegasan pantul $(41-63) \%$, tegangan putus $(0,53-1,03) \mathrm{kg} / \mathrm{cm} 2$, perpanjangan putus $(62,83-$ $112,5) \%$, ketahanan sobek $(0,37-0,76) \mathrm{kg} / \mathrm{cm} 2$ dan pampat tetap $(4,13-11,65)$ $\%$.

Data dari hasil pengujian sifat fisika tersebut dapat digunakan sebagai dasar untuk penyusunan rancangan Standar Nasional Indonesia Plastik Busa Untuk Jok Mobil. 


\section{PUSTAKA}

1. ASTM D. 3574 - 91 : Standard Test Method for Flexible Cellular Materials Slab, Bonded, and Molded Urethane Foams.

2. General Motor 6293 M - 1993 : Polyurethane Foam for Automotive Seating Aplication.

3. JIS K. 6401 - 1980 : Flexible UrethaneFoam for Cushion.

4. SNI 06-1004-1989 : Plastik Busa Poliuretan Lentur. 